\title{
Effect of Shift Report Training Program for Nurses on Quality of Reporting
}

\author{
Azza Galal Ahmed ${ }^{1}$, Mona Mostafa Shazly ${ }^{2}$, Rabab Mahmoud Hassan ${ }^{2}$ \\ ${ }^{1}$ Master student at faculty of nursing, Ain Shams University, \\ ${ }^{2}$ Professor of Nursing Administration Faculty of Nursing, Ain Shams University
}

\begin{abstract}
Background: Shift report has crucial on achieving effective, safe, and high quality communication when the responsibility for the patient care is transferred from one nurse to another in suitable manner.
\end{abstract}

Aim of Study: The study aimed to develop quality of reporting among nurses after implementation of shift report training program.

Subjects and Method: The study was conducted at Shoubra General Hospital which affiliated ministry of health hospitals Total bed capacity is (200) bed. Two groups of subjects participated in the study, namely head nurses, staff nurses; 50 head nurses and their assistants in the designated setting, the only selection criterion for this group was working in the selected units during the time of the study; and 129 staff nurses out from 194 according this equation. Three data collection tools were used to carry out this study namely, knowledge questionnaire sheet, Observational check list, Audit sheet. The study involved assessment, planning, implementation, and evaluation phases at the end of training and three months follow-up.

Results: No one of the staff nurses in the study sample had satisfactory total knowledge scores at the preintervention phase and reach $100 \%$ at the post-intervention and follow up phases. No one of the head nurses in the study sample had satisfactory total performance scores at the pre-intervention phase and reach $100 \%$ at the post- intervention phase, while the follow-up phase showed some declines, down to $70 \%$ in total performance scores.

Conclusion and Recommendations: There was a statistically significant correlation between head nurses' total knowledge, performance, and audit scores with p-value $>0.01$, also, there was a statistically significant correlation between nurses' total knowledge, performance, and audit scores with p-value $>0.01$. The study recommends Periodic assessment of head nurses and their staff for reporting skills. Regular implementation of training programs regarding shift report.

Keywords: Shift report, Training program, Nurses, Quality of reporting.

\section{Introduction}

Nursing is an art and a science by which people are assisted in learning to care for themselves whenever possible and cared for by others when they are, unable to meet their own needs. Nurses coordinate care and apply their knowledge and skills to deliver care. Breakdown of communication between, nurses can interfere with the client's treatment (Delaune and Ladner, 2016). Communication in, nursing is a journey to a destination of clear meaning. Nurses travel this road to help patients, and families heal and promote health and wholeness.
Communication? is at the heart of nursing and is essential in conveying caring and applying nursing skills and knowledge (Berman et al., 2015).

On a daily basis, in every "healthcare facility, the responsibility for the care of patients is transferred between care providers. This process occurs in active and interruptive environments that are typical of those in healthcare today. The communication of patient information to the next care provider can be known as "report," "end-of-shift report," "handoff," or "handover." This communicates the information necessary for 
patient care to continue as planned; and for the purpose of this Project, the term "handover" will be used. Three primary things are transferred during every handover: information, authority and responsibility (Epstin, 2017).

Intradepartmental communication at the unit level among nurses and other health caregivers has been identified as a key factor in patient safety, particularly during an interaction called nurse to nurse handoff (Kentucky and Streeter, 2018). Intradepartmental communication with other members of the healthcare team affects patient safety and the work environment. Breakdown in communication is the more frequent cause of serious injuries in healthcare settings when patients move from one nursing unit to another; so accurate communication is essential to prevent errors (World Health Organization, 2007).

The ability of the team members to, understand and communicate the information enables them to work together collaboratively and. coordinately (Reader et al., 2015). Communication of information in healthcare is a vital component to provide safe patient care. Communication is necessary to report critical patient changes in a timely clear manner; such communication may be from nurse to physician, from nurse to' patient, or from nurse to nurse as well as to other, members of the healthcare team (Harvery, 2017).

Reporting is the verbal communication' of data regarding the client's health status, needs, treatments, outcomes, and responses. When a report is. given, it needs to summarize the current critical information? that facilitates clinical decision making and continuity of care. Recording and reporting are based on the nursing process, standards of care, and legal and ethical principles. The nursing process provides structures for an organized report, a challenge inherent in verbal communication. In order to do efficient verbal communication and well 'organized report, the nurse must consider what needs to? be said, why it needs to be said, how to say it and what the expected' outcomes are needed. Considering these aspects of; reporting before the communication happen will provide a concise, organized report (Daniels et al., 2015).

There are three patient-centered positive outcomes associated with nurse-to-nurse bedside' shift report as patient empowerment, patient involvement and patient becoming an additional resource in diagnosis and treatment. Bedside shift reporting saves; time and allows the incoming nurse to ask questions. The nurses begin to know patients at the, beginning of the shift and doing assessments, so they can. carry out their clinical care tasks. This also gives them baseline, knowledge of the patients so they can monitor, changes or risks (Byers et al., 2019).

A bedside shift report reassures the' patient that the nursing staff works as a team that everyone 'knows the plan of care. By working together, patients witness a safe, professional transfer of? responsibilities; patients can ask questions, allowing the nurse and- patient an opportunity to share information; and promotes involvement and improved satisfaction and patients' empowerment (Anderson and Mangino, 2016). Bedside shift- report has been shown to empower nursing staff, improve patient involvement, and allow for a safe' transition of care between providers. It establishes and promotes. trusting relationships between 'patients and staff members, which serve as a foundation for teamwork (Bettyanne, 2015).

Continuing assessment of the patient's- needs and conditions requires accurate- documentation. This documentation helps promote the -continuity of care given by nurses and- other healthcare providers. Because one nurse cannot provide twenty-four-hour coverage, significant information- must be passed on to others through reports, nursing processes- notes and care plans (Berman et al., 2016).

Power is necessary to be able to- influence an individual or group. Nurses need power to be able to influence patients, physicians, and other healthcareprofessionals, as well as each other. Powerless nurses are ineffective- nurses, and the consequences of nurses' lack of power have only recently come to light. Powerless nurses are less satisfied with their jobs, and more susceptible to -burnout and depersonalization. Lack of nursing power may also contribute to poorer patient outcomes. Meanwhile, there are compelling reasons to promote power in nursing (Manjlovich, 2015).

Empowered employees provide exceptional service and experience this first-hand. Empowered employees have the power to make decisions without a supervisor. They are entitled to go off script, bend the rules, do what they see fit if they believe it is the right thing to do for the customer. More than any other kind of employee, the empowered employee is able to create a feeling of true customer service that ultimately yields much greater customer loyalty (Richard, 2015). 
Most managers would agree that feedback is essential in order to keep employees on course and to help them reach their goals. However, giving employees feedback is difficult for many managers. Effective managerial feedback can be defined as verbal and nonverbal communication with employees regarding their, performance, based on mutually agreed upon goals (Berman et al., 2016). Feedback is described as an, integral ingredient in the communication process because it lets everyone in the interaction know that the message, has been received and also lets the sender know how those, who received it have interrupted it. Feedback is evident from, both verbal and nonverbal responses equally and clarifies whether interpretation or understanding of the messages is mutual or shared (Timmins and McCabe, 2017).

Communication is the life blood of any, organization and its main purpose is to affect change to influence, action. It is the chain of understanding that integrates the members of an organization from top to bottom, bottom to top, and side to side (Basaavanthappa, 2009). It is important, that all healthcare team members communicate with each other regarding assessment, intervention outcomes, and client status. Poor communication can lead to frustration of members of the healthcare team, and poor, documentation of complications or severity lead to significant lost revenue. Also, it has significant impact on quality, costs and revenueand, affects patients, safety (Salman, 2010). Accurate documentation is needed to protect patients from fragmented and possibly, dangerous care (Perry et al., 2016).

Significance of the study: Special emphasis on the hand-over procedures and nursing personnel must be acquainted with the different types of (intra-departmental reports with periodic training and re-training to refresh nursing(personnel knowledge. Actually, the observation of handoff among staff nurses during change (of shifts in the study setting was inadequate and lead to lack of knowledge of (incoming nurse about all information related to the patient (Shazly, 2003). Therefore, the present study was conducted to (improve the intradepartmental communication among nurses through providing evaluative feedback regarding their (performance of shift report and finding out its effects on nurses' and patient's empowerment.

Aim of the Study: The aim of this study is to develop quality of reporting among nurses after implementation of shift report training program.

\section{Subjects and Method}

Research Design: Quasi experimental research design was used in carrying out the current study.

Setting: This study was conducted at Shoubra General Hospital which affiliated ministry of health hospitals. Total bed capacity is (200) bed. It consists of the following units and departments; medical department, surgical department, neonatal intensive care unit, intensive care unit, cardiac care unit, burn department, emergency department, obstetric and gynecological department, hemodialysis unit, pediatric department, and ten outpatient clinics.

Subjects: The study subjects consisted of two groups of subjects participated in the study, namely head nurses, staff nurses. Head nurses group: It consisted of 50 head nurses and their assistants in the designated setting. The only selection criterion for this group was working in the selected units during the time of the study. Staff nurses group: It included 129 staff nurses out from 194 according this equation.

Data collection tools: Three data collection tools were used to carry out this study namely, knowledge questionnaire sheet, Observational check list, Audit sheet.

\section{Knowledge questionnaire sheet: - (Appendix I)}

It aimed to assess nursess knowledge regarding shift report. This tool will consist of two parts:

Part 1: It aimed to collecting data regarding characteristics of study subject as, age, gender, qualifications, years of experience as well as attendance of training course

Part 2: It developed by, (Shazly, 2003, Abd- Elal, 2014 and Atef, 2015) and will be modified by the researcher. It included (40 multiple choice questions), cover certain scopes as definition of shift had, importance and content of shift hand over.

Scoring System: Nurses response were scored (one) for the correct answer and (zero) for incorrect answer. Mean and standard deviation was calculated and then converted into percent score. The knowledge was considered satisfactory if percent score was $60 \%$ or more and unsatisfactory if less than $60 \%$

2. An observational check list: (Appendix II): It aimed to assess nurses' performance regarding shift 
report It developed by (Shazly, 2003, Abd-Elal

2014 and Atef, 2015). It covers three main domains namely; 1) pre report hand over preparation, 2) practice during the hand over procedure, and 3) hand over the department.

Scoring System: The observation scoring systems were "done" and "not done" which scored one and zero respectively. The scores of the items of each part were summed up and the total divided by the number of items, giving a mean score for the part. These scores were converted to percent score. Total score of nurses' performance regarding shift report considered adequate if total percent score was $60 \%$ or more and inadequate if the total percent score was less than $60 \%$

3. Audit Sheet: This sheet was aimed to assess quality of report. It adopted from (Abed Elal 2014). It included the criteria for shift report (11 items) and the content of shift report (20 items)

Scoring System: Nurses' response was; "present", or "not present" and scored one and zero respectively. The scores of the items were summed up and the total divided by the number of items, giving a mean score. These scores were converted to percent score. Total score accepted if total percent score was $60 \%$ or more and not accepted if the total percent score was less than $60 \%$

Tools validity and reliability: Face and content validity of the tools was assessed by jury group consisted of five experts in nursing administration in faculty of nursing at, (Ain shams, Cairo university and shobra general hospital). Jury group members judge tools for comprehensiveness, accuracy and clarity in language. Based on their recommendations correction, addition and/or omission of some items were done. Study tools were tested for its internal consistency by Cronbach's Alpha. It was 0.783 for knowledge questionnaire sheet and 0.815 for the observation checklist.

Fieldwork: Once official permissions were obtained, the fieldwork was started. The researcher met with the nursing director of the hospital to determine the suitable time to collect the data and confirm the days and times to implement the training program. The study was carried out through an assessment of nurses' knowledge regarding shift report using a structured questionnaire sheet, nurses' performance regarding shift report were assessed using the observation checklist. The questionnaire sheet took from 20:30 minutes to be completed while the observation checklist took from 30:45 minutes.

Administrative Design: An approval to conduct the study was obtained from the Faculty of Nursing at AinShams University, and from Shoubra General Hospital which affiliated ministry of health hospitals.

Ethical Considerations: Prior study conduction, ethical approval was obtained from the scientific research ethical committee of the faculty of nursing, Ain Shams University. The researcher met both medical and nursing directors of the hospital where the nurses worked to clarify the aim of the study and take their approval. The researcher also met the study subjects to explain the purpose of the study and to obtain their approval to participate. They were reassured about the anonymity and confidentiality of the collected data, which was used only for the purpose of scientific research. The subjects' right to withdraw from the study at any time was assured.

Statistical Analysis: Data entry and statistical analysis were done using (SPSS) statistical software package. Quality control was at the stage of coding and data entry. Data were presented using descriptive statistics in the form of frequencies and percentage for qualitative variables; mean and standard deviation for quantitative variable. Qualitative categorical variables were compared Chi-square (X2) test; the hypothesis that the row and column variables are independent, without indicating strength or direction of the relationship, Analysis of variance (ANOVA) test. Statistical significance was considered at (P-value $<0.05)$.

\section{Results}

Table 1 showed that, half of head nurses $(50 \%)$ had from 30 to 40 years, majority of head nurses $(90 \%)$ were females and three fifth of them $(60 \%)$ were married, regarding half of them $(50 \%)$ had bachelor of nursing science. Majority of the head nurses $(80 \%)$ had $10-20$ years of experience.

Table 2 shows that nearly half of staff nurses (48.8\%) had more than 30 years, majority of staff nurses $(85.3 \%)$ were females and nearly two thirds of them (64.3\%) were married, nearly half of them (46.5\%) had technical institute diploma. Nearly two thirds of the staff nurses (65.1\%) had $5-10$ years of experience.

Table 3 displays, highly statistically significant improvement in all mean scores as well as in total mean 
of head nurses' shift report knowledge. There are highly significant changes between head nurses' shift report knowledge in the pre and post and between pre and follow up knowledge with p-value $<0.01$.

Table 4 illustrates that, highly statistically significant improvement in all mean scores as well as in total mean of staff nurses' knowledge. There are highly significant changes between staff nurses' knowledge in the pre and post and between pre and follow up knowledge with p-value $<0.01$.

Table 5 states that highly statistically significant improvement in all mean scores as well as in total mean of head nurses' performance. There are highly significant changes between head nurses' performance in the pre and post and between pre and follow up performance with p-value $<0.01$.

Table 6 indicates that highly statistically significant improvement in all mean scores as well as in total mean of staff nurses' performance. There are highly significant

Table 1: Demographic characteristics of head nurses in the study sample $(n=50)$

\begin{tabular}{|l|c|c|}
\hline Demographic characteristics & No & $\%$ \\
\hline 1. Age: & & \\
\hline - $<30$ years & 5 & 10 \\
\hline - $30-40$ years & 25 & 50 \\
\hline - >40 years & 20 & 40 \\
\hline 2. Gender: & & \\
\hline - Male & 5 & 10 \\
\hline - Female & 45 & 90 \\
\hline 3. Marital status: & 10 & 20 \\
\hline - Single & 30 & 60 \\
\hline - Married & 5 & 10 \\
\hline - Widowed & 5 & 10 \\
\hline - Divorced & & \\
\hline 4. Nursing qualification: & 19 & 48 \\
\hline - Doctorate in nursing science & 25 & 50 \\
\hline - Master in nursing science & 40 & 38 \\
\hline - Bachelor of nursing science & 25 & \\
\hline - High average diploma & & \\
\hline 5. Years of Experience & & \\
\hline - <10 years & & \\
\hline - $\geq 10$ years & & \\
\hline
\end{tabular}

changes between staff nurses' performance in the pre and post and between pre and follow up performance with p-value $<0.01$.

Table 7 demonstrates highly statistically significant improvement in all mean scores as well as in total mean of head nurses' audit scores. There are highly significant changes between head nurses' audit scores in the pre and post and between pre and follow up audit scores with p-value $<0.01$.

Table 8 shows that highly statistically significant improvement in all mean scores as well as in total mean of staff nurses' audit scores. There are highly significant changes between staff nurses' audit scores in the pre and post and between pre and follow up audit scores with p-value $<0.01$.

Table 9 shows that, there was a statistically significant correlation between nurses' total knowledge, performance, and audit scores with p-value $>0.01$.

Table 2: Demographic characteristics of staff nurses in the study sample $(n=129)$

\begin{tabular}{|l|l|l|}
\hline Demographic characteristics & No & $\%$ \\
\hline 1. Age: & 53 & 41.1 \\
\hline - <25 years & 13 & 10.1 \\
\hline - 25-30 years & 63 & 48.8 \\
\hline - >30 years
\end{tabular}

2. Gender:

\begin{tabular}{|l|c|c|}
\hline - Male & 19 & 14.7 \\
\hline - Female & 110 & 85.3 \\
\hline
\end{tabular}

\begin{tabular}{|l|c|c|}
\hline 3. Marital status: \\
\hline - Single & 21 & 16.3 \\
\hline - Married & 83 & 64.3 \\
\hline - Widowed & 6 & 4.7 \\
\hline - Divorced & 19 & 14.7 \\
\hline
\end{tabular}

\begin{tabular}{|l|l|c|}
\hline \multicolumn{4}{|l|}{ 4. Nursing qualification: } \\
\hline - Bachelor of nursing science & 38 & 29.5 \\
\hline - Technical institute diploma & 60 & 46.5 \\
\hline - Diploma in nursing & 31 & 24 \\
\hline \multicolumn{2}{|l}{ 5. Years of Experience } \\
\hline - <5 years & 20 & 15.5 \\
\hline - 5 - 10 years & 84 & 65.1 \\
\hline - >10 years & 25 & 19.4 \\
\hline
\end{tabular}


Table 3: Head nurses' total shift report knowledge mean scores throughout the intervention

\begin{tabular}{|c|c|c|c|c|c|c|}
\hline \multirow{3}{*}{ Items } & \multirow{3}{*}{ No. of Items } & \multicolumn{3}{|c|}{ Mean score } & \multirow{2}{*}{\multicolumn{2}{|c|}{ Paired Sample Test }} \\
\hline & & \multirow{2}{*}{$\begin{array}{c}\text { Pre } \\
\text { Mean } \pm \text { SD }\end{array}$} & \multirow{2}{*}{$\begin{array}{c}\text { Post } \\
\text { Mean } \pm \text { SD }\end{array}$} & \multirow{2}{*}{$\begin{array}{l}\text { Follow up } \\
\text { Mean } \pm \text { SD }\end{array}$} & & \\
\hline & & & & & P1 & $\mathbf{P 2}$ \\
\hline Communication skills & 11 & $2.2 \pm 4.42$ & $10.1 \pm 0.93$ & $7.6 \pm 1.52$ & $.000 * *$ & $.000 * *$ \\
\hline Shift report & 17 & $5.3 \pm 1.46$ & $15.1 \pm 1.39$ & $11.9 \pm 3.11$ & $.000 * *$ & $.000 * *$ \\
\hline Patient safety & 12 & $2.8 \pm 1.38$ & $11.3 \pm 0.52$ & $8.8 \pm 1.85$ & $.000 * *$ & $.000^{* *}$ \\
\hline Total knowledge & 40 & $10.6 \pm 3.93$ & $36.4 \pm 2.06$ & $29.3 \pm 5.62$ & $.000 * *$ & $.000 * *$ \\
\hline
\end{tabular}

Table 4: Staff nurses' total shift report knowledge mean throughout the intervention

\begin{tabular}{|c|c|c|c|c|c|c|}
\hline \multirow{3}{*}{$\begin{array}{l}\text { Total shift report } \\
\text { knowledge }\end{array}$} & \multirow{3}{*}{ No. of Items } & \multicolumn{3}{|c|}{ Mean score } & \multirow{2}{*}{\multicolumn{2}{|c|}{ Paired Sample Test }} \\
\hline & & \multirow{2}{*}{$\begin{array}{c}\text { Pre } \\
\text { Mean } \pm \text { SD }\end{array}$} & \multirow{2}{*}{$\begin{array}{c}\text { Post } \\
\text { Mean } \pm \text { SD }\end{array}$} & \multirow{2}{*}{$\begin{array}{l}\text { Follow up } \\
\text { Mean } \pm \text { SD }\end{array}$} & & \\
\hline & & & & & P1 & P2 \\
\hline Communication skills & 11 & $1.9 \pm 1.37$ & $10.1 \pm 0.64$ & $9.1 \pm 0.95$ & $.000 * *$ & $.000 * *$ \\
\hline Shift report & 17 & $2.9 \pm 1.82$ & $15.5 \pm 0.95$ & $13.2 \pm 1.74$ & $.000 * *$ & $.000 * *$ \\
\hline Patient safety & 12 & $1.8 \pm 1.16$ & $11.2 \pm 0.93$ & $9.3 \pm 1.68$ & $.000 * *$ & $.000 * *$ \\
\hline Total knowledge & 40 & $6.7 \pm 2.73$ & $36.7 \pm 1.26$ & $31.3 \pm 2.01$ & $.000 * *$ & $.000 * *$ \\
\hline
\end{tabular}

Table 5: Distribution of head nurses' total performance mean scores by the main categories throughout the intervention $(\mathbf{n}=\mathbf{5 0})$.

\begin{tabular}{|c|c|c|c|c|c|c|}
\hline \multirow{3}{*}{ Total performance } & \multirow{3}{*}{ No. of Items } & \multicolumn{3}{|c|}{ Mean score } & \multirow{2}{*}{\multicolumn{2}{|c|}{ Paired Sample Test }} \\
\hline & & Pre & Post & Follow up & & \\
\hline & & Mean \pm SD & Mean \pm SD & Mean \pm SD & P1 & $\mathbf{P 2}$ \\
\hline Pre report hand over preparation & 6 & $1.9 \pm 0.84$ & $5.7 \pm 0.46$ & $4.4 \pm 0.96$ & $.000 * *$ & $.000 * *$ \\
\hline Handover procedure & 45 & $7.2 \pm 5.74$ & $42.9 \pm 1.71$ & $31.2 \pm 4.21$ & $.000 * *$ & $.000 * *$ \\
\hline Handover the department & 8 & $1.05 \pm 0.67$ & $7.9 \pm 0.31$ & $4.7 \pm 1.52$ & $.000 * *$ & $.000 * *$ \\
\hline Total performance & 59 & $8 . .7 \pm 6.9$ & $56.6 \pm 1.89$ & $40.3 \pm 5.66$ & $.000 * *$ & $.000 * *$ \\
\hline
\end{tabular}

Table 6: Distribution of staff nurses' total performance mean scores by the main categories throughout the intervention $(\mathbf{n}=129)$.

\begin{tabular}{|l|c|c|c|c|c|c|}
\hline \multirow{2}{*}{ The main categories } & \multirow{2}{*}{ No. of Items } & \multicolumn{3}{|c|}{ Mean score } & \multicolumn{2}{|c|}{ Paired Sample Test } \\
\cline { 3 - 7 } & & Pre & Post & Follow up & \multicolumn{2}{c|}{ P1 } \\
\cline { 3 - 7 } & & Mean \pm SD & Mean \pm SD & Mean \pm SD & $.000^{* *}$ & $.000^{* *}$ \\
\hline Pre report hand over preparation & 6 & $1.6 \pm 1.77$ & $5.7 \pm 0.71$ & $5.3 \pm 1.28$ & $.000^{* *}$ & $.000^{* *}$ \\
\hline Handover procedure & 45 & $18.2 \pm 7.51$ & $40.1 \pm 5.51$ & $32.4 \pm 3.75$ & $.000^{* *}$ & $.000^{* *}$ \\
\hline Handover the department & 8 & $4.3 \pm 3.19$ & $7.3 \pm 0.56$ & $6.3 \pm 2.13$ & $.000^{* *}$ & $.000^{* *}$ \\
\hline Total performance & 59 & $23.7 \pm 8.46$ & $53.2 \pm 7.37$ & $44.1 \pm 5.46$ & & \\
\hline
\end{tabular}

Table 7: Distribution of head nurses' total audit mean scores by the main categories throughout the intervention $(\mathbf{n}=\mathbf{5 0})$.

\begin{tabular}{|c|c|c|c|c|c|c|}
\hline \multirow{3}{*}{ The main categories } & \multirow{3}{*}{ No. of Items } & \multicolumn{3}{|c|}{ Mean score } & \multirow{2}{*}{\multicolumn{2}{|c|}{ Paired Sample Test }} \\
\hline & & \multirow{2}{*}{$\begin{array}{c}\text { Pre } \\
\text { Mean } \pm \text { SD }\end{array}$} & \multirow{2}{*}{$\begin{array}{c}\text { Post } \\
\text { Mean } \pm \text { SD }\end{array}$} & \multirow{2}{*}{$\begin{array}{l}\text { Follow up } \\
\text { Mean } \pm \text { SD }\end{array}$} & & \\
\hline & & & & & $\mathbf{P 1}$ & $\mathbf{P 2}$ \\
\hline Criteria of shift report & 11 & $3.2 \pm 0.88$ & $10.8 \pm 0.61$ & $8.5 \pm 2.61$ & $.000 * *$ & $.000 * *$ \\
\hline Content about personal information & 7 & $2.4 \pm 1.29$ & $6.8 \pm 0.61$ & $5.1 \pm 1.15$ & $.000 * *$ & $.000^{* *}$ \\
\hline Content about nursing procedures & 13 & $1.8 \pm 1.74$ & $12.5 \pm 0.68$ & $9.7 \pm 2.9$ & $.000 * *$ & $.000 * *$ \\
\hline Total audit scores & 31 & $7.4 \pm 2.97$ & $30.1 \pm 1.23$ & $23.3 \pm 5.89$ & $.000 * *$ & $.000 * *$ \\
\hline
\end{tabular}


Table 8: Distribution of staff nurses' total audit mean scores by the main categories throughout the intervention $(\mathbf{n}=\mathbf{1 2 9})$.

\begin{tabular}{|c|c|c|c|c|c|c|}
\hline \multirow{3}{*}{ Total audit mean scores } & \multirow{3}{*}{ No. of Items } & \multicolumn{3}{|c|}{ Mean score } & \multirow{2}{*}{\multicolumn{2}{|c|}{ Paired Sample Test }} \\
\hline & & Pre & Post & Follow up & & \\
\hline & & Mean \pm SD & Mean \pm SD & Mean \pm SD & P1 & $\mathbf{P 2}$ \\
\hline Criteria of shift report & 11 & $3.7 \pm 2.16$ & $10.6 \pm 0.72$ & $8.4 \pm 1.56$ & $.000 * *$ & $.000^{* *}$ \\
\hline Content about personal information & 7 & $3.2 \pm 1.77$ & $6.8 \pm 0.78$ & $5.3 \pm 1.59$ & $.000 * *$ & $.000^{* *}$ \\
\hline Content about nursing procedures & 13 & $5.2 \pm 3.19$ & $12.5 \pm 0.23$ & $9.3 \pm 2.81$ & $.000 * *$ & $.000 * *$ \\
\hline Total audit scores & 31 & $12.3 \pm 4.56$ & $29.8 \pm 2.16$ & $23.1 \pm 4.57$ & $.000 * *$ & $.000 * *$ \\
\hline
\end{tabular}

Table 9: Correlation between staff nurses' total knowledge, performance, audit scores

\begin{tabular}{|l|l|c|c|c|}
\hline \multicolumn{2}{|c|}{} & Total knowledge scores & Total performance scores & Total audit scores \\
\hline \multirow{2}{*}{ Total knowledge scores } & $\mathrm{R}$ & 1 & & \\
\cline { 2 - 5 } & $\mathrm{p}$-value & - & & \\
\hline \multirow{2}{*}{ Total performance scores } & $\mathrm{R}$ & 0.436 & 1 & \\
\cline { 2 - 5 } & $\mathrm{p}$-value & $.000^{* *}$ & - & 1 \\
\hline \multirow{2}{*}{ Total audit scores } & $\mathrm{R}$ & 0.662 & 0.779 & - \\
\cline { 2 - 5 } & $\mathrm{p}$-value & $.000^{* *}$ & $.000^{* *}$ & \\
\hline
\end{tabular}

$(* *)$ Highly statistically significant at $\mathrm{p}<0.01$

\section{Discussion}

Getting a good nursing report before starting shift is vitally important. It is not only important for the nurse but for the patient as well. Nursing report is given at the end of the nurses shift to another nurse that will be taking over care for that particular patient. Nurses' shift reports are routine occurrences in healthcare organizations that are viewed as crucial for patient outcomes, patient safety and continuity of care. Nursing report is usually given in a location where other people cannot hear due to patient privacy (Inanloo, et al., 2017).

One of the major responsibilities of nursing profession is how to communicate, report, take report, and record information. Nursing report is the official exchange of information between nurses in written or oral form at the end of each shift. Besides recording the written report of nurses, oral report is a communication method which its purpose is to transfer essential and key information about patients' medical care. As mentioned, one of the practical reports of nurses is work shift delivery report when the responsible nurse for caring the patient provides the other nurses with a summary of patient's activities and condition at the time of leaving the unit to rest or deliver his or her shift (Ghosh, et al,
2018). So, the current study aimed to developing quality of reporting among nurses after implementation of shift report training program.

Regarding demographic characteristics of head nurses, the current study revealed that half of head nurses had from 30 to 40 years, majority of head nurses were females and three fifth of them were married, regarding half of them had bachelor of nursing science. Majority of the head nurses had $10-20$ years of experience. Nearly three quarter of the head nurses attended training courses.

This result was in agreement with Mio, Fasan, \& Costantini, (2020) who found that the majority of head nurses were female, and married. Also, this result was in congruence with Mardis, et al., (2016) who found that the majority of head nurses had bachelor of nursing science, and their year experience were from 10 to 20 years. Conversely, this result was in disagreement with Grimshaw, et al., (2020) who found that the majority of head nurses not attended training courses, and three quarter of them had technical institute of nursing.

Regarding demographic characteristics of nurses, the current study revealed that nearly half of nurses had 
more than 30 years, majority of participants were females and nearly two thirds of them were married, nearly half of them had technical institute diploma. Nearly two thirds of the nurses had 5-10 years of experience. Also, two third of the nurses attended training courses.

This result was in agreement with Inanloo, Mohammadi, \& Haghani, (2017) who found that the majority of nurses were female, and married. Conversely, this result was in disagreement with Ito, \& Iijima, (2018). who found that the majority of nurses had bachelor of nursing science, and their experience year were from 3 to 5 years.

Regarding participants' total knowledge throughout the intervention, the current study showed that no one of head nurses and nurses in the study sample had satisfactory total knowledge scores at the preintervention phase while all of them had satisfactory knowledge at the post-intervention. This result may be due to head nurses and staff nurses were very interested with training program that increased their knowledge.

This result was in congruence with Mitchell, et al., (2018) who found that the majority of nurses' knowledge about communication skills improved at post intervention phase after implementation of the program. Also, this result was in agreement with La Torre, et al., (2019) who found that majority of nurses' knowledge about shift report were generally low before the intervention, and improved after intervention.

Regarding participants' total performance scores, the current study revealed that no one of the head nurses and nurses in the study sample had satisfactory total performance scores at the pre-intervention phase while all of them had adequate performance at the postintervention phase. The follow-up phase showed some declines. This result may be due to staff nurses were compliance with training courses that improved their performance with shift report.

This result was in agreement with Biondi, Dumay, \& Monciardini, (2020) who found that the no one of nurses had satisfactory performance during hand-over procedure before the intervention. Also, this result was in agreement with Buus, Hoeck, \& Hamilton, (2017) who found that majority of nurses had satisfactory performance during hand-over procedure after the intervention.

Regarding participants' total audit scores, the current study revealed that no one of the head nurses and nurses in the study sample had satisfactory total audit scores at the pre-intervention phase while all of them had satisfactory audit scores at the post-intervention phase, while the follow-up phase showed some declines.

This result was supported with Hajibabaee, et al., (2014) who found that the majority of nurses had unsatisfactory total audit scores at the pre-intervention phase. Also, this result was in agreement with Waage, et al., (2014) who found that the majority of nurses had satisfactory total audit scores at the post intervention phase.

Regarding correlation between head nurses' total knowledge, performance, audit scores, the current study revealed that there was a statistically significant correlation between head nurses' total knowledge, performance, and audit scores

This result was supported with Prang, \& JelsnessJørgensen,. (2014) who found that there was a statistically significant correlation between head nurses' total knowledge, and audit scores. Also, this result was in congruence with Mardis, et al., (2016) who found that there was a statistically significant correlation between head nurses' total knowledge, and performance.

Regarding correlation between staff nurses' total knowledge, performance, audit scores, the current study revealed that there was a statistically significant correlation between nurses' total knowledge, performance, and audit scores

This result was in agreement with Inanloo, Mohammadi, \& Haghani, (2017) who found that there was there was a statistically significant correlation between nurses' total performance, and audit scores. Conversely, this result was in disagreement with Ito, \& Iijima, (2018) who found that there was no statistically significant correlation between nurses' total knowledge, and audit scores.

\section{Conclusion}

The current study concluded that: Presence of improvement in nurses, knowledge and performance regarding shift hand over and quality of report after implementing the program.

Recommendation: In the light of results of this study, the following recommendations were suggested: 
- Periodic evaluation of the nurses practice regarding shift report

- Conducting training program regarding shift report in different settings

- Provide continuous support to the nursing staff to enhance their writing skills.

\section{References}

1. Abdalla, E. A., Abdoon, I. H., Osman, B., Osman, W. J., \& Mohamed, E. M. (2020). Perception of medication errors' causes and reporting among Sudanese nurses in teaching hospitals. Applied Nursing Research, 51, 151207.

2. AbuAlRub, R. F., Al-Akour, N. A., \& Alatari, N. H. (2015). Perceptions of reporting practices and barriers to reporting incidents among registered nurses and physicians in accredited and nonaccredited J ordanian hospitals. Journal of Clinical Nursing, 24(19-20), 2973-2982.

3. ALasdy, S. M. H. (2019). The Implications of the Shift towards Standard Financial Reporting Specialist for Small and Medium-Sized Companies to Attract Foreign Investment in the Iraqi Environment. Open Access Library Journal, 6(02)

4. Beck, C., Dumay, J., \& Frost, G. (2017). In pursuit of a $\square$ single source of truth $\square$ : from threatened legitimacy to integrated reporting. Journal of Business Ethics, 141(1), 191-205.

5. Biondi, L., Dumay, J., \& Monciardini, D. (2020). Using the International Integrated Reporting Framework to comply with EU Directive 2014/95/ EU: can we afford another reporting façade? Meditari Accountancy Research.

6. Burd, B., John, S. N., Michelle, B. S, \& Trilli,. N. (2016). Bedside Reporting at Change of Shift.

7. Buus, N., Hoeck, B., \& Hamilton, B. E. (2017). Nurses' shift reports: a systematic literature search and critical review of qualitative field studies. Journal of Clinical Nursing, 26(19-20), 2891-2906.

8. Deng, J., Chen, S., Chen, J., Ding, H., Deng, D., \& Xie, Z. (2018). Self-reporting colorimetric analysis of drug release by molecular imprinted structural color contact lens. ACS applied materials \& interfaces, 10(40), 34611-34617.

9. Dumay, J., La Torre, M., Rea, M. A., \& Abhayawansa, S. (2020). A journey towards a safe harbour: The rhetorical process of the International
Medico-legal Update, April-June 2021, Vol. 21, No. 2

97

Integrated Reporting Council. The British Accounting Review, 52(2), 100836.

10. Ferguson, T. D., \& Howell, T. L. (2015). Bedside reporting: protocols for improving patient care. Nursing Clinics, 50(4), 735-747.

11. Foster, C. L., Abraham, S. P., \& Gillum, D. R. (2019). Emergency Room Nurses' Views on Bedside Shift Reporting. International Journal of Studies in Nursing, 4(4), 55.

12. Galtung, F. (2019). How impactful is Fair Trade? A paradigm shift in reporting would tell a better story. Journal of Fair Trade, 1(2), 40-48.

13. Ghosh, K., Curl, E., Goodwin, M., Morrell, P., \& Guidroz, P. (2018, January). An exploratory study on how to improve bedside change-of-shift process: Evidence from one hospital using technology to support verbal reporting. In Proceedings of the 51st Hawaii International Conference on System Sciences.

14. Gökten, P. O., \& Marşap, B. (2017). Paradigm shift in corporate reporting. Accounting and corporate reporting-today and tomorrow.

15. Grimshaw, J., Hatch, D., Willard, M., \& Abraham, S. (2020). A qualitative study of the change-ofshift report at the patients' bedside. The health care manager, 39(2), 66-76.

16. Hajibabaee, F., Joolaee, S., Peyravi, H., AlijanyRenany, H., Bahrani, N., \& Haghani, H. (2014). Medication error reporting in Tehran: a survey. Journal of nursing management, 22(3), 304-310.

17. Hill, L. G. (2020). Back to the future: Considerations in use and reporting of the retrospective pretest. International Journal of Behavioral Development, 44(2), 184-191.

18. Inanloo, A., Mohammadi, N., \& Haghani, H. (2017). The effect of shift reporting training using the SBAR tool on the performance of nurses working in intensive care units. Journal of ClientCentered Nursing Care, 3(1), 51-56.

19. Ito, K., \& Iijima, M. (2018). The Paradigm Shift from Financial Reporting to Integrated Reporting. Journal of Human Resource Management, 6(3), 8594.

20. Khammarnia, M., Ravangard, R., Barfar, E., \& Setoodehzadeh, F. (2015). Medical errors and barriers to reporting in ten hospitals in southern Iran. The Malaysian Journal of Medical Sciences: MJMS, 22(4), 57. 
21. La Torre, M., Bernardi, C., Guthrie, J., \& Dumay, J. (2019). Integrated reporting and integrating thinking: Practical challenges. In Challenges in managing sustainable business (pp. 25-54). Palgrave Macmillan, Cham.

22. Lindskog, E. D. (2020). U.S. Patent Application No. 16/698,028.

23. Mardis, T., Mardis, M., Davis, J., Justice, E. M., Holdinsky, S. R., Donnelly, J., ... \& Riesenberg, L. A. (2016). Bedside shift-to-shift handoffs: a systematic review of the literature. Journal of nursing care quality, 31(1), 54-60.

24. McGinn, C. (2017). Nurses Perceptions' of Bedside Reporting on an Intensive Care Unit Following Implementation.

25. Melone, D. F. (2017). Implementation of Intentional Grounding and Bedside Shift Reporting on Patients' Call Light Usage and Patient Satisfaction (Doctoral dissertation, Grand Canyon University).

26. Mio, C., Fasan, M., \& Costantini, A. (2020). Materiality in integrated and sustainability reporting: A paradigm shift? Business Strategy and the Environment, 29(1), 306-320.

27. Mitchell, A., Gudeczauskas, K., Therrien, A., \& Zauher, A. (2018). Bedside reporting is a key to communication. ARCHIVOS DE MEDICINA, 3(1), 13 .

28. Nnabuife, E . P. R. (2018). Prostate ImagingReporting and Data System (PI-RADS)-A Paradigm Shift. Prostate.

29. Ofori-Atta, J., Binienda, M., \& Chalupka, S. (2015). Bedside shift report: Implications for patient safety and quality of care. Nursing 2019, 45(8), 1-4.
30. Okaro, S., Okafor, G., (2019). From Sustainability To Integrated Reporting-A Paradigm Shift For Nigeria'S Global Competitiveness. International Journal of Accounting and Finance (IJAF), 8(1), 38-49.

31. Peplonska, B., Bukowska, A., \& Sobala, W. (2015). Association of rotating night shift work with BMI and abdominal obesity among nurses and midwives. PloS one, 10(7), e0133761.

32. Potter, B., Adams, C. A., Singh, P. J., \& York, J. (2016). Exploring the implications of integrated reporting for social investment (disclosures). The British Accounting Review, 48(3), 283-296.

33. Prang, I. W., \& Jelsness-Jørgensen, L. P. (2014). Should I report? A qualitative study of barriers to incident reporting among nurses working in nursing homes. Geriatric Nursing, 35(6), 441-447.

34. Tan Jr, A. K. (2015). Emphasizing caring components in nurse-patient-nurse bedside reporting. International journal of caring sciences, 8(1), 188-193.

35. Vrbnjak, D., Denieffe, S., O'Gorman, C., \& Pajnkihar, M. (2016). Barriers to reporting medication errors and near misses among nurses: A systematic review. International journal of nursing studies, 63, 162-178.

36. Waage, S., Pallesen, S., Moen, B. E., Magerøy, N., Flo, E., Di Milia, L., \& Bjorvatn, B. (2014). Predictors of shift work disorder among nurses: a longitudinal study. Sleep medicine, 15(12), 14491455 . 